\title{
Linking the North American dipole to the Pacific meridional mode
}

\author{
Ruiqiang Ding ${ }^{1,2}$, Jianping $\mathrm{Li}^{2,3}$, Yu-heng Tseng ${ }^{4}$, Cheng Sun ${ }^{3}$, Yang $\mathrm{Li}^{5}$, Nan \\ Xing ${ }^{6}$, and Xiaofeng $\mathrm{Li}^{7}$
}

1. State Key Laboratory of Numerical Modeling for Atmospheric Sciences and Geophysical Fluid Dynamics (LASG), Institute of Atmospheric Physics, Chinese Academy of Sciences, Beijing 100029, China

2. Laboratory for Regional Oceanography and Numerical Modeling, Qingdao National Laboratory for Marine Science and Technology, Qingdao 266061, China

3. College of Global Change and Earth System Sciences (GCESS), Beijing Normal University, Beijing 100875, China

4. Institute of Oceanography, National Taiwan University, Taipei 10617, Taiwan

5. Plateau Atmosphere and Environment Key Laboratory of Sichuan Province, Chengdu University of Information Technology, Chengdu 610225, China

6. Beijing Meteorological Observatory, Beijing 100089, China

7. School of Civil Engineering and Geosciences, Newcastle University, Newcastle upon Tyne NE1 7RU, UK

(submitted to Journal of Geophysical Research-Atmosphere)

(Second revision)

February 22, 2019

Corresponding author:

Dr. Ruiqiang Ding

State Key Laboratory of Numerical Modeling for Atmospheric Sciences and Geophysical

Fluid Dynamics (LASG), Institute of Atmospheric Physics, Chinese Academy of Sciences,

Beijing 100029, China

Tel: +86-10-82995181; Fax: +86-10-82995172

Email: drq@mail.iap.ac.cn 


\section{Abstract}

The North American dipole (NAD) represents a meridional dipole of sea level pressure (SLP) anomalies over the western tropical North Atlantic and northeastern North America. This study demonstrates that the NAD is intimately linked to the development of the Pacific meridional mode (PMM). In addition to the North Pacific Oscillation (NPO), the NAD provides another important remote forcing source to trigger the PMM. The NAD influences the PMM through both direct and indirect pathways. The direct effect is that the winter NAD influences the sea surface temperature (SST) and surface winds over the northeastern subtropical Pacific (NESP) through concurrent anticyclonic flow associated with the NAD, which tends to generate a weak initial warming over the NESP region during late winter and early spring. The indirect effect is that the NAD first induces SST cooling over the northern tropical Atlantic (NTA) during spring, and the NTA SST cooling then generates a low-level anticyclonic flow anomaly over the NESP, which further strengthens the surface warming over the NESP, thereby causing the development of the PMM in the following months. The NAD can also exert an influence on the El Niño-Southern Oscillation (ENSO) through its effects on the PMM. In particular, El Niño episodes led by the combined NAD-PMM events tend to take the form of the Central Pacific El Niño, rather than the canonical eastern Pacific El Niño. We suggest that a better understanding of the NAD-PMM-ENSO dynamic link could be useful for the prediction of different types of El Niño event. 


\section{Introduction}

Previous studies have suggested that atmospheric variability originating outside the tropical Pacific may influence the onset of the El Niño-Southern Oscillation (ENSO) [e.g., Li, 1990; Vimont et al., 2001, 2003a, b; Anderson, 2003, 2013; Jin and Kirtman, 2009; Alexander et al., 2010; Yu et al., 2010; Yu and Kim, 2011; Hong et al., 2014; Ding et al., 2015a, b, 2017a; Tseng et al., 2017]. In particular, the North Pacific Oscillation (NPO), the second leading mode of sea level pressure (SLP) variability over the North Pacific [Walker and Bliss, 1932; Rogers, 1981], has been shown to affect ENSO onset through the seasonal footprinting mechanism (SFM) [Vimont et al., 2003a, b]. The SFM hypothesized that fluctuations in the wintertime (hereafter, seasons refer to those for the northern hemisphere) NPO leave a footprint in sea surface temperatures (SST) by altering surface heat fluxes. These SST anomalies in turn persist until summer in the subtropical North Pacific. The overlying atmosphere in turn responds to these SSTs, resulting in surface zonal wind anomalies over the equatorial Pacific that are conducive to initiating an ENSO event. In addition to the SST signature, changes in the wind stress curl associated with the NPO drive an anomalous meridional Sverdrup transport that ultimately produces a buildup of heat content in the equatorial Pacific subsurface, which can subsequently favor the development of an ENSO event (the trade wind charging mechanism) [Anderson, 2004; Anderson et al., 2013].

A particularly important part of the NPO-induced SST footprint is a meridional gradient of SST anomalies in the northeastern subtropical Pacific (NESP) that couples 
strongly to anomalous southwesterlies in the northeasterly trade regime, referred to as the Pacific meridional mode (PMM) [Chiang and Vimont, 2004]. Chang et al. [2007] indicated that the PMM is driven by the NPO by changing the northeasterly trade winds on its southern flank during winter. Zonal wind stress anomalies associated with the PMM can act as a wind stress trigger for ENSO events [Chang et al., 2007; Larson and Kirtman, 2013] by exciting equatorial Kelvin waves that alter the thermocline depth and in turn the SST in the eastern equatorial Pacific [Thomas and Vimont, 2016]. The Atlantic counterpart to the PMM is referred to as the Atlantic meridional mode (AMM) [Chiang and Vimont, 2004]. Similarly, a few studies have demonstrated the existence of a close connection between extratropical atmospheric variability such as the North Atlantic Oscillation (NAO) [Hurrell, 1995; Li and Wang, 2003], AMM, and the Atlantic equatorial mode (often called the Atlantic ENSO mode) [Servain et al., 1999; Czaja et al., 2002].

The aforementioned studies documented the respective influences of extratropical atmospheric variability over the North Pacific (North Atlantic) on tropical Pacific (Atlantic) variability through the meridional modes. Recently, Ding et al. [2017b] reported that a meridional dipole of SLP anomalies over the western tropical North Atlantic and northeastern North America, called the North American dipole (NAD), could influence ENSO variability. They demonstrated that the mechanism through the NAD influences ENSO is similar to the subtropical teleconnection mechanism proposed by Ham et al. [2013] to illustrate the effect of SST anomalies in the northern tropical Atlantic (NTA) on subsequent ENSO events. 
That is, the wintertime NAD forces the NTA negative SST anomalies during spring. The NTA cooling can lead to a low-level anticyclonic flow over the NESP that then generates a low-level cyclonic flow over the western North Pacific over the course of the following months. This cyclonic flow generates westerly anomalies over the western equatorial Pacific that may trigger an El Niño event the following winter. While Ding et al. [2017b] have discussed the influences of the NAD on SST and surface winds over the NESP, where the PMM is defined, the connection between the NAD and PMM and its relevant dynamical processes have not been documented.

The present study aims to investigate the delayed effect of the wintertime NAD on the PMM. In contrast to most previous studies that mainly stressed the impact of North Pacific atmospheric variability on the PMM [Chang et al., 2007; Zhang et al., 2009; Yu et al., 2010; Yu and Kim, 2011], we will show that the NAD-like atmospheric variability originating from North America and the North Atlantic may also have an important impact on the PMM. We will illustrate that the NAD can directly exert an effect on the PMM through concurrent anticyclonic flow associated with the NAD, different from the subtropical teleconnection mechanism of Ham et al. [2013] that highlights the vital role of the NTA SST in influencing tropical Pacific variability. In addition to building the relationship between the NAD and PMM, we further explore the role of the PMM in linking the NAD to ENSO. We will show that the PMM also acts as an effective conduit for the NAD and NTA SST influence on ENSO. The rest of this paper is structured as follows. In section 2, the various datasets and indices employed are described. Statistical links between the NAD and PMM are 
presented in section 3. Possible mechanisms for the connections between the NAD and PMM are then discussed in section 4. Section 5 examines the connection between the NAD and PMM in the Coupled Model Intercomparison Project Phase 5 (CMIP5) pre-industrial simulations. Section 6 investigates the importance of the PMM in linking the NAD to ENSO. Our major findings are summarized and discussed in section 7 .

\section{Data and methods}

\section{a. Observed and modeled datasets}

Atmospheric fields including SLP, surface winds, and stream function employed in this study originate from the National Centers for Environmental Prediction/National Center for Atmospheric Research (NCEP/NCAR) project (1948-2015) [Kalnay et al., 1996]. The precipitation field employed in our analysis is from the Climate Prediction Center (CPC) Merged Analysis of Precipitation (CMAP) dataset (1979-2015) [Xie and Arkin, 1997]. The CMAP precipitation dataset is on a $2.5^{\circ}$ by $2.5^{\circ}$ horizontal grid globally. The SST data are from the National Oceanic and Atmospheric Administration (NOAA) Extended Reconstructed SST, version 4 [ERSSTv4; Smith et al., 2008]. The ERSSTv4 dataset resides on a horizontal resolution of $2^{\circ} \times 2^{\circ}$ and runs from 1854 to 2015 . The ocean temperature, total downward heat flux at surface, and oceanic circulation data are from the NCEP Global Ocean Data Assimilation System (GODAS) (1980-2015) [Behringer et al., 1998]. This product has a $1 / 3^{\circ} \times 1 / 3^{\circ}$ horizontal resolution in the tropics, and has 40 
vertical levels with $10-\mathrm{m}$ resolution near the sea surface.

Our analysis focuses on the period 1979-2015, as the reanalysis atmosphere, SST, and precipitation data are all obtainable for this period. Monthly anomalies were calculated by removing the 1981 to 2010 climatological means for each month. All data are linearly detrended before calculation.

In addition to the observational data, we also used the pre-industrial simulations from 23 climate models participated in the CMIP5. Given that the simulation length varies from model to model, outputs from the last 100 years of each run were used for the analysis.

\section{b. The NAD index}

The NAD represents a meridional dipole of SLP anomalies over the western tropical North Atlantic and northeastern North America. Following Ding et al. [2017b], the NAD index was defined as the difference of normalized SLP anomalies between the southern $\left(93-58^{\circ} \mathrm{W}, 9-29^{\circ} \mathrm{N}\right)$ and northern $\left(77-43^{\circ} \mathrm{W}, 53-68^{\circ} \mathrm{N}\right)$ poles. It should be noted that the NAD is different from the North American zonal dipole, which has been recently referred to in the literature as an east-west dipole concerning temperature extremes across North America [Wang et al., 2014, 2015].

The NAD is strongest in winter and weakest in summer [Ding et al., 2017b]. Figure 1a shows the spatial pattern of winter [December-February (DJF)] averaged SLP anomalies correlated with the winter NAD index. We note that the NAD-related SLP pattern exhibits a north-south dipole structure over northeastern North America 
to the western tropical North Atlantic. Figure $1 \mathrm{~b}$ shows the time series of the winter NAD index. As pointed out by Ding et al. [2017b], although SLP anomalies associated with the NAD, NAO, and the Pacific-North America (PNA) teleconnection pattern [Horel and Wallace, 1981; Wallace and Gutzler, 1981] overlap over some regions of the North America and western North Atlantic, the NAD has its own variability independent of the NAO and PNA.

\section{c. The PMM index}

Following the method of Chiang and Vimont [2004], the PMM spatial pattern is defined by applying Maximum Covariance Analysis (MCA) to tropical Pacific SST and $10 \mathrm{~m}$ winds over the region $\left(175^{\circ} \mathrm{E}-95^{\circ} \mathrm{W}, 21^{\circ} \mathrm{S}-32^{\circ} \mathrm{N}\right)$. To define the spatial pattern, the data are first spatially smoothed (three longitude by two latitude points). Next, the seasonal cycle is removed, the data are detrended, a three month running mean is applied to the data, and influences of the equatorial Pacific Cold Tongue Index (SST averaged over $180^{\circ}-90^{\circ} \mathrm{W}, 6^{\circ} \mathrm{S}-6^{\circ} \mathrm{N}$ ) are subtracted (via linear regression) from each spatial point. After the PMM spatial pattern was determined, the two monthly time series (referred to as the PMM-wind index and the PMM-SST index, respectively) were obtained by projecting the $10 \mathrm{~m}$ wind or SST field onto the corresponding spatial pattern resulting from the MCA. Chiang and Vimont [2004] reported that the PMM-wind index leads the PMM-SST index by one month, and the PMM-SST index peaks in variance during spring [March-May (MAM)], following the late winter/early spring [January-March (JFM)] peak variance in the PMM-wind 
index.

\section{Establishing the NAD-PMM relationship}

Figure 2a shows the correlations of the PMM-wind index during April-June (AMJ) with the previous winter SLP anomalies. The PMM pattern is indeed significantly related to a previous winter NPO-like dipole pattern of SLP anomalies over the North Pacific, in agreement with previous work [Chang et al., 2007; Zhang et al., 2009; Yu et al., 2010; Yu and Kim, 2011; Tseng et al., 2017]. In addition, a meridional SLP dipole pattern over eastern North America and the North Atlantic is also found to be significantly related to the following PMM during the AMJ season. This dipole pattern closely resembles the NAD-related SLP pattern in Figure 1a. Considering that the NAD is relatively independent of the NPO at different lag/lead times (not shown), these results show that in addition to the NPO, the NAD may be another important remote forcing source to affect the PMM.

To examine the possible connection between the NAD and PMM, we show in Figure $2 \mathrm{~b}$ the lead-lag correlations of the winter (DJF-averaged) NAD index with 3-month averaged PMM-wind (green line) and PMM-SST (red line) indices for the period 1979-2015. Hereafter, we denote the year in which the PMM develops as year(0) and the preceding and following years as year(-1) and year(+1), respectively. Significant correlation (at the 95\% level) between the PMM-wind and NAD indices first occurs during February-April (FMA), lagging the peak of the NAD during DJF by approximately two months. After FMA, the correlations increase and exceed the 
99\% significance level during AMJ. These significant correlations persist through the following late fall and early winter [October-December (OND)]. For the PMM-SST index, significant correlation (at the 95\% level) first occurs during AMJ and also persists until the following OND. In comparison, significant correlation of the PMM-wind index occurs about two months earlier than that of the PMM-SST index, which almost coincides with the lagged relationship between the PMM-wind and PMM-SST indices, as noted previously by Chiang and Vimont [2004]. A similar lead/lag correlation of the DJF NAO index with 3-month averaged PMM indices was also performed, but no significant correlations are found (not shown), indicating that in contrast with the NAO, the NAD may be more closely linked to the PMM.

Figure 3a shows the composite differences in the seasonal evolution of the PMM-wind (red bars) and PMM-SST (green bars) indices between strongly positive NAD cases (1988, 1989, 1990, 1991, 2002, and 2006) and strongly negative NAD cases (1982, 1995, 1997, 2009, and 2010). These strongly positive (negative) NAD cases are defined as winters (DJF) when the NAD index exceeds one positive (negative) standard deviation. Significant values of the PMM-wind index begin to appear during FMA, peak during AMJ, and persist through the following fall (SON). Significant PMM-SST anomalies begin to appear during AMJ and peak during JJA, lagging the peak of the PMM-wind anomalies by about two months. Significant values of the PMM-SST index also persist through SON. These results from the composite analysis are generally consistent with those from the correlation analysis presented above. 
We next examine the time series of the AMJ-averaged PMM-wind index from 1980 to 2014 (Figure 3b). From this it can be seen that five out of six strongly positive

208 NAD cases (denoted by red bars) are followed by a positive value of the PMM-wind 209 index during the AMJ season (see also the scatterplot of the DJF NAD index versus 210 the following AMJ PMM-wind index in Figure 3c). This is especially the case for the 211 1989-1992 period, during which persistent positive anomalies of the PMM-wind

212 index are preceded by strongly positive NAD-like SLP anomalies. Similarly, four out 213 of five strongly negative NAD cases (denoted by blue bars) are followed by a 214 negative value of the PMM-wind index during the AMJ season (see also Figure 3c). In 215 particular, all four negative values of the PMM-wind index preceded by strongly 216 negative NAD cases exceed one negative standard deviation. These relationships 217 support the result that the NAD during winter has an in-phase relationship with the 218 PMM during the following late spring and early summer. Even though the 219 observational analysis presented above demonstrates a close relationship between the 220 NAD and PMM, it has limitations due to the relatively short records with very few 221 NAD or PMM cases. As shown later, further analyses using longer datasets from the CMIP5 models support the results based on the observational data. NAD and PMM at seasonal timescales. To identify possible mechanisms explaining

\section{Potential mechanisms linking the NAD to the PMM}

The results thus far have shown a close connection between variability in the the dynamical link between the NAD and PMM, we next examine the evolutions of 
the composite differences in SST, surface wind, and precipitation anomalies between strongly positive and negative NAD cases (Figure 4).

During winter (DJF), when the NAD peaks, the low-level anomalous anticyclonic flow associated with the southern pole of the NAD covers most regions of the NTA and NESP. The anticyclonic flow gives rise to northerly and southerly flow anomalies on its east and west flanks, respectively. The northerly flow anomaly strengthens northeasterly trade winds and thereby enhances the latent heat flux release from ocean to atmosphere (not shown), resulting in surface cooling over the NTA region. On the contrary, the southerly flow anomaly leads to surface warming over the NESP region through the reduced northeasterly trade winds. At the same time, anomalous easterlies on the south flank of the NESP anticyclonic flow lead to surface cooling over the eastern Pacific cold tongue region by enhanced upwelling [Kug et al., 2009].

During spring (MAM), when the NAD enters its decaying phase, positive and negative SST anomalies occur respectively over the NESP and cold tongue regions, resulting in a meridional SST dipole (i.e., the PMM SST pattern) in the eastern Pacific. At this time, the NTA SST cooling reaches its peak, and can subsequently suppress the convective activity and precipitation over the off-equatorial region in the vicinity of the Atlantic ITCZ, which then produces a low-level anticyclonic flow anomaly over the NESP as a Matsuno-Gill type Rossby wave response [Ham et al., 2013]. To further verify the role of the NTA SST cooling in influencing circulation anomalies over the NESP, we performed a simple numerical experiment using the Matsuno-Gill 
model [Matsuno, 1966; Gill, 1980]. The location of the prescribed ideal cooling

252 source over the NTA region for the model (Figure 5a) is consistent with the

253 distribution of maximum negative precipitation anomalies associated with the NAD

254 during MAM in Figure 4b. Corresponding to the cooling over the NTA region, there

255 are low-level anticyclonic circulation responses over the NESP region (Figure 5b),

256 leading support to the idea that the NTA SST cooling can force a low-level

257 anticyclonic flow anomaly over the NESP.

258 The anticyclonic flow anomaly due to the NTA SST cooling can strengthen and

259 sustain the anomalous anticyclonic flow over the NESP region, which may act to

260 further reinforce positive SST anomalies over the NESP region and negative SST

261 anomalies over the cold tongue region, leading to the development of the PMM. As

262 the NESP warming gradually develops, the overlying atmosphere then responds by

263 modulating the strength of northeasterly trade winds that strengthens the initial SST

264 warming, forming a positive wind-evaporation-SST (WES) feedback [Xie and

265 Philander, 1994]. The NESP warming extends southwestward and reaches the central

266 equatorial Pacific during summer via the WES feedback, finally triggering the onset

267 of an ENSO event.

To examine how much the net heat flux and ocean horizontal/vertical advections

269 associated with the NAD contribute to the developing PMM SST pattern, a budget

270 analysis of the mixed layer temperature is applied separately to the subtropical

$271\left(140-110^{\circ} \mathrm{W}, 8-20^{\circ} \mathrm{N}\right)$ and equatorial $\left(120-70^{\circ} \mathrm{W}, 5^{\circ} \mathrm{S}-5^{\circ} \mathrm{N}\right)$ poles of the $\mathrm{PMM}$

272 meridional SST dipole. Following Kang et al. [2001] and Li et al. [2015], the heat 
budget equation can be derived as follows:

$$
\frac{\partial T^{\prime}}{\partial t}=-\bar{u} \frac{\partial T^{\prime}}{\partial x}-u^{\prime} \frac{\partial \bar{T}}{\partial x}-u^{\prime} \frac{\partial T^{\prime}}{\partial x}-\bar{v} \frac{\partial T^{\prime}}{\partial y}-v^{\prime} \frac{\partial \bar{T}}{\partial y}-v^{\prime} \frac{\partial T^{\prime}}{\partial y}-\bar{w} \frac{\partial T^{\prime}}{\partial z}-w^{\prime} \frac{\partial \bar{T}}{\partial z}-w^{\prime} \frac{\partial T^{\prime}}{\partial z}+Q^{\prime}+R
$$

where overbars and primes indicate the monthly climatology and anomaly, respectively. The variables $u, v, w, T, Q^{\prime}$, and $R$ denote zonal current, meridional current, vertical current, ocean temperature, thermal forcing, and residual terms, respectively.

Figure $6 \mathrm{a}, \mathrm{b}$ show the evolutions of dominant terms in the SST equation for the subtropical and equatorial poles of the PMM meridional SST dipole, respectively. Note that the warming tendency of the subtropical pole is strongest in June, while the cooling tendency of the equatorial pole is strongest in May. The magnitude of the cooling tendency of the equatorial pole is greater than that of the warming tendency of the subtropical pole, indicating that the development of the cooling over the equatorial eastern Pacific is relatively faster than that of the warming over the NESP. For the subtropical pole, the net heat flux term is positive from previous winter to summer, and its magnitude is also large compared with the SST tendency. This is related to the reduced latent heat flux release from ocean to atmosphere due to the weakened trade winds and the enhanced incoming shortwave radiation due to the NESP anticyclonic flow (not shown). This term plays a crucial role in the SST development of the subtropical pole. The zonal and meridional advection terms are very small (not shown). Among vertical advection terms, the nonlinear vertical advection term $\left(-w^{\prime} \partial T^{\prime} / \partial z\right)$ is relatively large, and is mostly in phase with the SST tendency (Figure 6a), indicating that this term is also important for the SST tendency of the subtropical 
pole. Presumably, this is because there is an anomalous downwelling due to the anomalous anticyclonic flow over the NESP region that weakens the vertical advection of the anomalous cool water in the subsurface to the surface layer. The other vertical advection terms are relatively small (not shown).

For the equatorial pole, the anomalous vertical advection term $\left(-w^{\prime} \partial \bar{T} / \partial z\right)$ is almost in phase with the observed SST tendency, and its magnitude is also comparable to the observed tendency (Figure 6b). This indicates that this term contributes much to the evolution of the eastern equatorial Pacific SST anomalies associated with the NAD. Because the mean vertical temperature gradient $(\partial \bar{T} / \partial z)$ is negative in the eastern equatorial Pacific, the anomalous upwelling $\left(w^{\prime}<0\right)$ due to anomalous easterlies on the south flank of the NESP anticyclonic flow will lead to a continuous cooling tendency $\left(-w^{\prime} \partial \bar{T} / \partial z<0\right)$. In addition, the anomalous zonal advection term $\left(-u^{\prime} \partial \bar{T} / \partial x\right)$, the meridional advection term $\left(-\bar{v} \partial T^{\prime} / \partial y\right)$, and the net heat flux term are relatively large, and exhibit a cooling tendency from previous winter to summer. These three terms also play a role in the development of significant negative SST anomalies in the eastern equatorial Pacific. The other terms are relatively small during the developing phase of the eastern equatorial Pacific SST cooling (not shown).

Based on the budget analysis, it is revealed that the SST evolution of the subtropical pole is somewhat different from that of the equatorial pole. The net heat flux term $\left(Q_{n e t}^{\prime}\right)$ is very important for the development of positive SST anomalies over the NESP, indicating that subtropical NESP SST anomalies associated the NAD are predominantly thermodynamically-driven. In contrast, the anomalous vertical 
advection term $\left(-w^{\prime} \partial \bar{T} / \partial z\right)$ is dominated in the development of negative SST anomalies over the eastern equatorial Pacific, indicating that ocean dynamics (i.e., changes in equatorial upwelling in response to anomalous winds associated with the NAD) play a crucial role in affecting the SST there. According to the above analysis, these terms are all related to the NESP anticyclonic flow anomaly associated with the NAD. This implies that the NESP anticyclonic flow anomaly is a key source of the PMM meridional SST dipole pattern. Once the NESP anticyclonic flow anomaly is produced by the NAD, it tends to induce positive and negative SST anomalies respectively over the NESP and eastern equatorial Pacific regions, contributing to a meridional SST dipole pattern over the eastern Pacific.

One may wonder why the NAD exerts a persistent effect on the PMM. We hypothesize that this is because the NAD potentially affects the PMM through both direct and indirect pathways. The direct effect is through concurrent anticyclonic flow associated with the wintertime NAD. The indirect effect is that the NAD first induces negative SST anomalies over the NTA region, and the NTA SST cooling in turn produces a low-level anticyclonic flow anomaly over the NESP as a Matsuno-Gill type Rossby wave response [Ham et al., 2013]. Figure 7a illustrates the sequential evolution of these direct and indirect effects. Once the positive NAD-like SLP anomalies develop during winter (DJF), their associated anticyclonic flow anomaly induces negative SST anomalies over the NTA as well as weak positive SST anomalies over the NESP (or a meridional SST dipole over the eastern Pacific) during spring (MAM). As the NAD gradually decays, the anomalous NTA SST in turn 
produces an anticyclonic flow anomaly over the NESP as Matsuno-Gill type Rossby

340 wave response, due to the anomalous convective activity [Ham et al., 2013]. Through

341 this interbasin interaction between the Atlantic and Pacific Oceans, the anomalous

342 anticyclonic flow over the NESP further strengthens and persists through summer

343 (JJA). At the same time, the meridional SST dipole over the eastern Pacific that

344 strongly couples to the anomalous anticyclonic flow gradually develops during spring

345 and persists through summer. In this way, the NAD exerts a delayed or prolonged

346 effect on the PMM through the persistent NESP anticyclonic flow anomaly. Given

347 that the observational records involve a mixture of various climate signals, the

348 influences of the NAD on the PMM through the direct and indirect pathways require

349 further study using a coupled general circulation model (CGCM).

We note that the subtropical anticyclonic flow anomaly associated with the southern pole of the NAD shows two peaks (Figure 7a). The first peak occurs during DJF, concurrent with the peak phase of the NAD, which tends to generate weak (not

353 significant at the $95 \%$ confidence level) positive SST anomalies over the NESP region

354 during late winter and early spring. The second peak occurs during March-June 355 (MAMJ) when the anticyclonic flow anomaly experiences a further westward 356 extension into the NESP region, which in turn further amplifies positive SST 357 anomalies in the region. According to our results, this second peak is very likely to be 358 related to the NAD-induced NTA SST anomalies, which occur around the same time 359 (peaking during spring and persisting until summer). Furthermore, we note that the 360 peak correlation between the DJF NAD index and NTA SST area-averaged over 
$\left(85^{\circ} \mathrm{W}-20^{\circ} \mathrm{E}, 0-15^{\circ} \mathrm{N}\right)$ occur during MAM, while the peak correlation between the MAM NTA SST and PMM-SST index occurs during ASO (Figure 7b). This may explain why the correlation the DJF NAD index and PMM-SST index reaches maximum during ASO, as seen in Figure $2 b$.

\section{CMIP5 multi-model outputs}

We further used the CMIP5 pre-industrial simulations to evaluate if the CMIP5 models can reproduce the relationship between the NAD and PMM. The spatial patterns and intensities of the PMM have been shown to be reasonably simulated by most of the CMIP5 models [Lin et al., 2015]. Most of the CMIP5 models can also capture the NAD-like SLP dipole pattern reasonably well (not shown). The names of 23 CMIP5 models used in the present study are provided in Figure 8. As there are at least 26 and at most 35 NAD cases in the 100-year simulations of these 23 CMIP5 models, the composite analyses may provide more robust results. Next, we examined the composite differences of the AMJ-averaged PMM-wind and PMM-SST indices between strongly positive and negative NAD cases in the CMIP5 models. We found that 17 of 23 CMIP5 models simulate significant (at the $95 \%$ confidence level) PMM-wind signals after strong NAD cases, with only six of them producing weak or insignificant PMM-wind signal (Figure 8a). The multi-model ensemble (MME) of 23 CMIP5 models shows that strong NAD cases during the DJF season are followed by a significant value of the PMM-wind index during the following AMJ season. Similarly, 16 of 23 CMIP5 models simulate significant PMM-SST signals after strong NAD 
cases, with only seven producing weak PMM-SST signal (Figure 8b). These CMIP5 model results, which are consistent with results based on observations, support that the PMM pattern the AMJ season is related to the previous winter NAD variability.

The evolutions of SST and surface wind anomalies for strong NAD cases are also evaluated in the CMIP5 pre-industrial simulations. Because the SST and surface wind magnitudes differ considerably among the models, composite SST and surface anomalies are normalized by their temporal standard deviations before taking the multi-model ensemble mean. Figure 9 shows the ensemble-mean composite map of the 3-month averaged SST and surface wind anomalies between strongly positive and negative NAD cases. Consistent with the observation, the CMIP5 model result also shows that there are significant negative SST anomalies over the NTA region during winter (DJF). These NTA SST anomalies persist until the following spring (i.e., MAM) and subsequently force a low-level anticyclonic flow anomaly over the NESP, strengthening the latter and in turn leading to the development of the PMM SST pattern. These processes involved in the influence of the NAD on the PMM in the CMIP5 pre-industrial simulations are generally similar to those in observations. The similarity with observations supports the idea that the NAD can indeed exert a marked effect on the PMM through its influence on the NTA SST and then NESP anticyclonic flow. However, note that the CMIP5 multi-model ensemble mean fails to simulate the warming over the central equatorial Pacific during the JJA and SON seasons as shown in observational analysis (Figure 4), possibly because the equatorward extension of the PMM is not well simulated in most of the CMIP5 models [Lin et al., 2015]. 
Larson and Kirtman [2014] showed that the models in the North American Multimodel Ensemble (NMME) prediction experiment also do not reproduce the predictive potential of the PMM for the central equatorial Pacific warming seen in observations.

\section{Dynamic links among the NAD, PMM, and ENSO}

As mentioned earlier, previous studies have demonstrated that the NPO may be an important atmospheric forcing source of the PMM, and the PMM in turn works as an effective conduit through which the NPO influences ENSO [Chang et al., 2007; Zhang et al., 2009; Yu et al., 2010; Yu and Kim, 2011]. As such, it is important to ask whether a similar dynamic link between the NAD, PMM, and ENSO exists. As shown in Figure 4, the NAD first induces a PMM-like meridional SST dipole during spring, and the WES feedback then extends the PMM-related SST anomalies over the NESP southwestward towards the central equatorial Pacific during summer, which can subsequently force anomalous westerly over the western equatorial Pacific that may trigger an ENSO event the following winter. This suggests that the PMM may also play a vital role in linking the NAD to ENSO.

To further explore the role of the PMM in linking the NAD to ENSO, we calculated the partial correlations between the winter NAD index and the tropical Pacific SST anomalies a year later by removing the linear effect of the AMJ PMM-wind index. Without removing the PMM effect, significant positive and negative correlations between the winter NAD index and SST anomalies the 
following winter are seen in the central and western equatorial Pacific, respectively (Figure 10a), consistent with the results of Ding et al. [2017b]. However, after removing the PMM effect, significant correlations are absent in most regions of the equatorial Pacific, and the central equatorial Pacific warming becomes indistinct (Figure 10b).

Furthermore, when the DJF NAD index and the following AMJ PMM-wind index are stratified by whether they have the opposite or same sign, we note that the correlation between the winter NAD index and the Niño4 index a year later is high $(R$ $=0.88$ ) when the NAD index has the same sign as the PMM-wind index (Figure 10c), whereas the correlation is only -0.37 when they have the opposite sign (Figure 10d). Similar results can be obtained if the MAM NTA SST area-averaged over $\left(85^{\circ} \mathrm{W}-20^{\circ} \mathrm{E}, 0-15^{\circ} \mathrm{N}\right)$ is used instead of the DJF NAD index (not shown). The results presented above support the hypothesis that the PMM may provide an important bridge (or conduit) in the connection between the North Atlantic forcings (including the NAD and NTA SST) and ENSO.

The preceding analysis establishes a possible dynamic link between the NAD, PMM, and ENSO. It should be noted that the existence of this dynamic link may have important implications for prediction and understanding of the Central Pacific El Niño (CP El Niño) [Yu and Kao, 2007; Kao and Yu, 2009]; also termed the Date Line El Niño [Larkin and Harrison, 2005], El Niño Modoki [Ashok et al., 2007], or warm-pool El Niño [Kug et al., 2009] whose action center is over the central equatorial Pacific, different from the canonical eastern Pacific El Niño (EP El Niño). 
Note in Figure 4 that the NAD initiates the warming over the central equatorial

452

453

Pacific through its influence on the PMM during summer, and afterwards this warming does not extend to the eastern Pacific, but instead is sustained and trapped in the central equatorial Pacific. This suggests that the NAD tends to be closely related to the development of the CP El Niño, as noted in Ding et al. [2017b].

The key distinctive role of the NAD is to induce both the PMM and persistent anomalous easterly over the eastern equatorial Pacific through its delayed effect on the NTA SST (see Figure 4). The equatorial easterly flow over the eastern Pacific is known to suppress SST warming by anomalous upwelling through Ekman transport [Kug et al., 2009], and therefore limits the eastward propagation of warm SST anomalies originally over the central equatorial Pacific. In this way, the NAD may play an important role in the development of the CP El Niño. The fact that the NAD acts as an effective extratropical forcing of the CP El Niño supports the idea that the CP El Niño may be an extratropically excited mode of the tropical Pacific variability [Yu and Kim, 2011].

\section{Summary and discussion}

The focus of this study was to examine the relationship between the North American SLP dipole (NAD) and Pacific meridional mode (PMM). We have found that beyond the well-known influence of the NPO, the NAD could have a significant impact on the development and evolution of the PMM, as supported by significant correlations of the wintertime NAD index with the PMM indices (including the 
PMM-wind and PMM-SST indices) for lead times of several months to almost a year.

We present a potential schematic diagram in Figure 11 that summarizes two dominant pathways through which the winter NAD affects the subsequent PMM. The winter NAD can affect the surface winds and SST over the NESP immediately after the peak of the NAD through concurrent anticyclonic flow associated with the NAD, which tends to generate a weak initial warming over the NESP region during late winter and early spring. In addition to this direct pathway, the winter NAD can induce SST cooling over the NTA region during spring. Then, the NTA SST cooling produces a low-level anticyclonic flow anomaly over the NESP as a Matsuno-Gill type Rossby wave response [Ham et al., 2013], which further strengthens the anomalous anticyclonic flow and surface warming over the NESP, thereby causing the development of the PMM in the following months. In this way, the NAD exerts a delayed or prolonged effect on the PMM through the persistent NESP anticyclonic flow anomaly.

A heat budget analysis reveals that the NESP anticyclonic flow associated with the NAD influences the subtropical and equatorial poles of the PMM in a different way. The net heat flux term $\left(Q_{n e t}^{\prime}\right)$ due to the weakened trade winds on the west flank of the NESP anticyclonic flow is very important for the development of positive SST anomalies over the subtropical pole of the PMM, while the anomalous vertical advection term $\left(-w^{\prime} \partial \bar{T} / \partial z\right)$ due to anomalous easterlies on the south flank of the NESP anticyclonic flow makes a major contribution to the development of negative SST anomalies over the equatorial pole of the PMM. 

NESP may extend equatorward through the WES feedback that in turn initiates the central equatorial Pacific warming during summer. Therefore, the PMM plays a vital role in linking the NAD to ENSO. It follows that there may exist a new dynamic link among the NAD, PMM, and ENSO at seasonal timescales. In contrast to the known NPO-PMM-ENSO link [Yu and Kim, 2011; Kim et al., 2012; Lin et al., 2015], this NAD-PMM-ENSO link also appears to be closely linked to the CP-type El Niño.

Given that the ability to predict the CP El Niño is limited and has a shorter lead time compared with the EP El Niño [Imada et al., 2015], this new link may offer a new perspective on prediction and understanding of the CP El Niño. through the PMM, it has limitations due to the limited number of available NAD, PMM, or CP El Niño events in observations. The role of the NAD in the generation of the CP El Niño needs further investigation using a CGCM that can properly simulate noted that CP El Niño events have occurred frequently since the 1990s [Lee and McPhaden, 2010]. Interestingly, both the relationships between the NAD and CP El

513 Niño (its variability represented by the Niño4 index) [Ding et al., 2017b], and 514 between the PMM and CP El Niño [Yu et al., 2015] show a consistent strengthening from the 1990s onwards. This implies that the role of the NAD in triggering the CP El Niño through the PMM conduit may be stronger after the 1990s when CP El Niño

517 events are frequently observed. Given the strengthened NAD influence on the 
subsequent $\mathrm{CP}$ El Niño, further research is also needed to enhance scientific understanding of the NAD-PMM-CP El Niño dynamic link and to consider the implications of this dynamic link in terms of improving predictions of different types of El Niño event.

It is also important to note that because both the NAD and NPO exert substantial influences on the PMM, the NAD influence on the PMM possibly interferes or interacts with the NPO effect, depending on the sign of their indices [Ding et al., 2017b]. In Figure 3b, there is one strongly positive NAD case that is not followed by a positive value of the PMM-wind index during the AMJ season, and also one strongly negative NAD case that is not followed by a negative value of the AMJ PMM-wind index. This breakdown of the NAD-PMM relationship in these two cases is possibly because of the interference between the NPO- and NAD-related SST and wind anomalies over the NESP region. This implies that we should also consider the influence of the NPO when judging whether the NAD exerts a marked effect on the PMM, and vice versa.

\section{Acknowledgments.}

This work was jointly supported by the 973 project of China (2016YFA0601801), and the National Program on Global Change and Air-Sea Interaction (GASI-IPOVAI-03, GASI-IPOVAI-06). The CMAP precipitation data set was obtained from the NASA Goddard Space Flight Center (available online at 
541 https://www.esrl.noaa.gov/psd/data/gridded/data.cmap.html). The atmospheric

542 reanalysis data set was obtained from the NCEP-NCAR (available online at

543 https://www.esrl.noaa.gov/psd/data/gridded/data.ncep.reanalysis.html). The oceanic

544 circulation data set was from the GODAS (available online at

545 https://www.cpc.ncep.noaa.gov/products/GODAS/). The ERSSTv4 data set was

546 obtained from the NOAA (available online at

547 https://www.esrl.noaa.gov/psd/data/gridded/data.noaa.ersst.v4.html). The PMM SST

548 and wind indices are available online at

549 http://www.esrl.noaa.gov/psd/data/timeseries/monthly/PMM/.

550

551

552

553

554

555

556

557

558

559

560

561

562

\section{References}

Alexander, M. A., D. J. Vimont, P. Chang, and J. D. Scott (2010) The impact of extratropical atmospheric variability on ENSO: Testing the seasonal footprinting mechanism using coupled model experiments, J. Clim., 23, 2885-2901.

Anderson, B. T. (2003) Tropical Pacific sea-surface temperatures and preceding sea level pressure anomalies in the subtropical North Pacific, J. Geophys. Res., 108, D23, doi:10.1029/2003JD003805.

Anderson, B. T. (2004), Investigation of a large-scale mode of ocean-atmosphere variability and its relation to tropical Pacific sea surface temperature anomalies, $J$. Clim., 17, 4089-4098. 
563

564

565

566

567

568

569

570

571

572

573

574

575

576

577

578

579

580

581

582

583

584

Anderson, B. T., R. C. Perez, and A. Karspeck (2013) Triggering of El Niño onset through trade wind-induced charging of the equatorial Pacific, Geophys. Res. Lett., 40, 1212-1216, doi:10.1002/grl.50200.

Ashok, K., S. K. Behera, S. A. Rao, Y. H. Weng, and T. Yamagata, 2007: El Niño Modoki and its possible teleconnection. J. Geophys. Res., 112, C11007, doi:10.1029/2006JC003798.

Behringer, D. W., M. Ji, and A. Leetmaa (1998) An improved coupled model for ENSO prediction and implications for ocean initialization, Part I: The ocean data assimilation system, Mon. Wea. Rev., 126, 1013-1021.

Chang, P., L. Zhang, R. Saravanan, D. J. Vimont, J. C. H. Chiang, L. Ji, H. Seidel, M. K. Tippett (2007) Pacific meridional mode and El Niño-Southern Oscillation, Geophys. Res. Lett., 34, L16608, doi:10.1029/2007GL030302.

Chiang, J., and D. J. Vimont (2004) Analogous Pacific and Atlantic meridional modes of tropical atmosphere-ocean variability, J. Clim., 17, 4143-4158.

Czaja, A., P. der Varrt, and J. Marshall (2002) A diagnostic study of the role of remote forcing in tropical Atlantic variability, J. Clim., 15, 3280-3290.

Ding, R. Q., J. P. Li, Y. H. Tseng, C. Sun, and Y. P. Guo (2015a) The Victoria mode in the North Pacific linking extratropical sea level pressure variations to ENSO, $J$. Geophys. Res., 120, 27-45, doi: 10.1002/2014JD022221.

Ding, R. Q., J. P. Li, Y. H. Tseng, and C. Q. Yuan (2015b) Influence of the North Pacific Victoria mode on the Pacific ITCZ summer precipitation, J. Geophys. Res., 120, 964-979, doi:10.1002/2014JD022364 
Ding, R. Q., J. P. Li, Y. H. Tseng, C. Sun, and F. Xie (2017a) Joint impact of North and South Pacific extratropical atmospheric variability on the onset of ENSO events, J. Geophys. Res., 122, 279-298, doi:10.1002/2016JD025502.

Ding, R. Q., J. P. Li, Y. H. Tseng, C. Sun, and F. Zheng (2017b) Linking a sea level pressure anomaly dipole over North America to the central Pacific El Niño, Clim. Dyn., 49, 1321-1339.

Gill, A. E. (1980) Some simple solutions for heat-induced tropical circulation, Quart. J. Roy. Meteor. Soc., 106, 447-462.

Ham, Y. G.., J. S. Kug, J. Y. Park, and F. F. Jin (2013) Sea surface temperature in the north tropical Atlantic as a trigger for El Niño/Southern Oscillation events, Nat. Geosci., 6, 112-116.

Hong, L. C., LinHo, and F. F. Jin (2014) A Southern Hemisphere booster of super El Niño, Geophys. Res. Lett., 41, 2142-2149, doi:10.1002/2014GL059370.

Horel, J. D., and J. M. Wallace (1981) Planetary-scale atmospheric phenomena associated with the Southern Oscillation, Mon. Wea. Rev., 109, 813-829.

Hurrell, J. W. (1995) Decadal trends in the North Atlantic Oscillation: Regional temperatures and precipitation, Science, 269, 676-679.

Imada, Y., H. Tatebe, M. Ishii, Y. Chikamoto, M. Mori, M. Arai, M. Watanabe, and M. Kimoto (2015) Predictability of two types of El Niño assessed using an extended seasonal prediction system by MIROC, Mon. Wea. Rev., 143, $4597-4617$.

Jin, D., and B. P. Kirtman (2009) Why the Southern Hemisphere ENSO responses 
608

609

610

611

612

613

614

615

616

617

618

619

620

621

622

623

624

625

626

627

628

Kalnay, E., and Coauthors (1996) The NCEP-NCAR 40-Year Reanalysis Project, Bull. Amer. Meteor. Soc., 77, 437-471.

Kang, I. S., S. I. An, and F. F. Jin (2001) A systematic approximation of the SST anomaly equation for ENSO, J. Meteor. Soc. Japan, 79, 1-10.

Kao, H. Y., and J. Y. Yu (2009) Contrasting eastern Pacific and central Pacific types of ENSO, J. Clim., 22, 615-632.

Kim, S. T., J. Y. Yu, A. Kumar, and H. Wang (2012) Examination of the two types of ENSO in the NCEP CFS model and its extratropical associations, Mon. Wea. Rev., 140, 1908-1923.

Kug, J. S., F. F. Jin, and S. I. An (2009) Two types of El Niño events: Cold tongue El Niño and warm pool El Niño, J. Clim., 22, 1499-1515.

Larkin, N. K., and D. E. Harrison (2005) Global seasonal temperature and precipitation anomalies during El Niño autumn and winter, Geophys. Res. Lett., 32, L16705, doi:10.1029/2005GL022860.

Larson, S. M., and B. P. Kirtman (2013) The Pacific Meridional Mode as a trigger for ENSO in a high-resolution coupled model, Geophys. Res. Lett., 40, 3189-3194.

Larson, S. M., and B. P. Kirtman (2014) The Pacific meridional mode as an ENSO precursor and predictor in the North American Multimodel Ensemble, J. Clim., 27, 7018-7032.

Lee, T., and M. J. McPhaden (2010) Increasing intensity of El Niño in the central-equatorial Pacific, Geophys. Res. Lett., 37, L14603, 
630 Li, C. Y. (1990) Interaction between anomalous winter monsoon in East Asia and El $631 \quad$ Niño events, Adv. Atmos. Sci., 7, 36-46.

632

633

634

635

636

637

638

639

640

641

642

643

644

645

646

647

648

649

650

Li, J. P., and J. X. L. Wang (2003) A new North Atlantic Oscillation index and its variability, Adv. Atmos. Sci., 20, 661-676.

Li, Y., J. P. Li, W. J. Zhang, X. Zhao, F. Xie, and F. Zheng (2015) Ocean dynamical processes associated with the tropical Pacific cold tongue mode, J. Geophys. Res., 120, 6149-6435, doi:10.1002/2015JC010814.

Lin, C. Y., J. Y. Yu, and H. H. Hsu (2015) CMIP5 model simulations of the Pacific meridional mode and its connection to the two types of ENSO, Int. J. Climatol., $35,2352-2358$.

Matsuno, T. (1966) Quasi-geostrophic motions in the equatorial area, J. Meteor. Soc. Japan, 44, 25-43.

Rogers, J. C. (1981) The North Pacific Oscillation, J. Climatol., 1, 39-57.

Servain, J., I. Wainer, J. WcCreary, and A. Dessier (1999) Relationship between the equatorial and meridional modes of climatic variability in the tropical Atlantic, Geophys. Res. Lett., 26, 485-488, doi:10.1029/1999GL900014.

Smith, T. M., R. W. Reynolds, T. C. Peterson, and J. Lawrimore (2008) Improvements to NOAA's historical merged land-ocean surface temperature analysis (1880-2006), J. Clim., 21, 2283-2296.

Thomas, E. E., and D. J. Vimont (2016) Modeling the mechanisms of linear and nonlinear ENSO responses to the Pacific meridional mode, J. Clim., 29, 
652

Tseng, Y. H., R. Q. Ding, and X. M. Huang (2017) The warm blob in the northeastern Pacific-the bridge leading to the 2015/16 El Niño, Environ. Res. Lett., 12, 054019.

Vimont., D. J., D. S. Battisti, and A. C. Hirst (2001) Footprinting: A seasonal connection between the tropics and mid-latitudes, Geophys. Res. Lett., 28, 3923-3926.

Vimont, D. J., J. M. Wallace, and D. S. Battisti (2003a) The seasonal footprinting mechanism in the Pacific: Implications for ENSO, J. Clim., 16, 2668-2675.

Vimont, D. J., D. S. Battisti, and A. C. Hirst (2003b) The seasonal footprinting mechanism in the CSIRO general circulation models, J. Clim., 16, 2653-2667.

Walker, G. T., and E. W. Bliss (1932) World weather V, Mem. Roy. Meteor. Soc., 4, 53-84.

Wallace, J. M., and D. S. Gutzler (1981) Teleconnections in the geopotential height field during the northern hemisphere winter, Mon. Wea. Rev., 109, 784-812.

Wang, S. Y., L. Hipps, R. R. Gillies, and J. H. Yoon (2014) Probable causes of the abnormal ridge accompanying the 2013-2014 California drought: ENSO precursor and anthropogenic warming footprint, Geophys. Res. Lett., 41, 3220-3226.

Wang, S. Y., W. Huang, and H. J. Yoon (2015) The North American winter 'dipole' and extremes activity: A CMIP5 assessment, Atmos. Sci. Lett., 16, 338-345.

Xie, P., and P. A. Arkin (1997) Global precipitation: A 17-year monthly analysis based 
673

674

675

676

677

678

679

680

681

682

683

684

685

686

687

688

689

690

691

on gauge observations, satellite estimates, and numerical model outputs, Bull. Amer. Meteor. Soc., 78, 2539-2558.

Xie, S. P., and S. G. H. Philander (1994) A coupled ocean-atmosphere model of relevance to the ITCZ in the eastern Pacific, Tellus, 46A, 340-350.

Yu, J. Y., and H. Y. Kao (2007) Decadal changes of ENSO persistence barrier in SST and ocean heat content indices: 1958-2001, J. Geophys. Res., 112, 125-138.

Yu, J. Y., H. Y. Kao, and T. Lee (2010) Subtropics-related interannual sea surface temperature variability in the central equatorial Pacific, J. Clim., 23, 2869-2884.

Yu, J. Y., and S. T. Kim (2011) Relationships between extratropical sea level pressure variations and the central Pacific and eastern Pacific types of ENSO, J. Clim., 24, $708-720$.

Yu, J. Y., P. K. Kao, H. Paek, H. H. Hsu, C. W. Hung, M. M. Lu, and S. I. An (2015) Linking emergence of the central Pacific El Niño to the Atlantic multidecadal oscillation, J. Clim., 28, 651-662.

Zhang, L., P. Chang, and L. Ji (2009) Linking the Pacific meridional mode to ENSO: Coupled model analysis, J. Clim., 22, 3488-3505. 
Figure 1. (a) Spatial pattern of winter [December-February (DJF)] averaged SLP anomalies correlated with the concurrent NAD index. Areas with a correlation significant at or above the $95 \%$ confidence level based on a two-tailed Student- $t$ test are shaded. (b) Time series of the winter (DJF) NAD index. To isolate the index (SST averaged over the region $\left.170-120^{\circ} \mathrm{W}, 5^{\circ} \mathrm{S}-5^{\circ} \mathrm{N}\right)$.

Figure 2. (a) Correlations of the AMJ-averaged PMM-wind index with the previous 

the years with strongly positive and negative NAD cases during the previous winter are denoted by red and blue bars, respectively. (c) Scatterplot of the DJF-averaged NAD index versus the following AMJ-averaged PMM-wind index. The correlation coefficient between the NAD and PMM-wind indices is given in the upper left corner.

Figure 4. Composite differences of the 3-month averaged SST $\left({ }^{\circ} \mathrm{C}\right.$; shaded), surface wind ( $\mathrm{m} \mathrm{s}^{-1}$; vectors), and precipitation ( $\mathrm{mm} \mathrm{day}^{-1}$; stippled) anomalies between strongly positive and negative NAD cases for (a) DJF concurrent with the NAD, and several lead times ((b) MAM, (c) JJA, and (d) SON). Only SST and surface wind anomalies significant at the $95 \%$ confidence level based on a $t$-test are shown. Positive (green) and negative (red) precipitation anomalies significant at the $95 \%$ confidence level are stippled.

Figure 5. (a) Distribution of the prescribed ideal cooling over the NTA region for the Matsuno-Gill model. The location of the prescribed ideal cooling source is consistent with the distribution of maximum negative precipitation anomalies during MAM in Figure 4b, with strength decreasing from the center to the surroundings. (b) Analytical solutions for horizontal winds forced by the cooling in (a).

Figure 6. (a) Composites differences of dominant terms (Unit: ${ }^{\circ} \mathrm{C}$ month ${ }^{-1}$ ) in the SST equation for the subtropical $\left(140-110^{\circ} \mathrm{W}, 8-20^{\circ} \mathrm{N}\right)$ pole of the PMM between strongly positive and negative NAD cases. (b) As in (a) but for composites 
differences of dominant terms in the SST equation for the equatorial $\left(120-70^{\circ} \mathrm{W}\right.$, $\left.5^{\circ} \mathrm{S}-5^{\circ} \mathrm{N}\right)$ pole of the PMM.

Figure 7. (a) Lead-lag regressions of the 3-month running mean subtropical stream function at $850 \mathrm{hPa}$ (meridionally averaged over $9^{\circ}-29^{\circ} \mathrm{N} ; 10^{7} \mathrm{~m}^{2} \mathrm{~s}^{-1}$; shaded) and SST (meridionally averaged over $5^{\circ}-20^{\circ} \mathrm{N} ;{ }^{\circ} \mathrm{C}$; contours) onto the winter [December(-1)-February(0)] NAD index from September(-1) to December(0). Only stream function and SST anomalies significant at the 95\% confidence level are shown. (b) Lead-lag correlations of the DJF NAD index with 3-month averaged NTA SST area-averaged over $\left(85^{\circ} \mathrm{W}-20^{\circ} \mathrm{E}, 0-15^{\circ} \mathrm{N}\right)$ (red line), and lead-lag correlations of the MAM NTA SST with 3-month averaged PMM-SST index (green line). The horizontal dashed lines show the $95 \%$ and $99 \%$ confidence levels, respectively.

Figure 8. Composite differences of the AMJ-averaged (a) PMM-wind and (b) PMM-SST indices between strongly positive and negative NAD cases in 23 CMIP5 models. Also shown the multi-model ensemble (MME) of 23 CMIP5 models. Error bars indicate the $95 \%$ confidence intervals based on a $t$-test.

Figure 9. Ensemble-mean composite differences of the 3-month averaged SST $\left({ }^{\circ} \mathrm{C}\right.$; shaded) and surface wind ( $\mathrm{m} \mathrm{s}^{-1}$; vectors) anomalies between strongly positive and negative NAD cases from 23 CMIP5 models for (a) DJF concurrent with the NAD, and several lead times ((b) MAM, (c) JJA, and (d) SON). Only SST and surface wind anomalies significant at the $95 \%$ confidence level based on a $t$-test are shown. 
Figure 10. (a) Correlation map of the winter (DJF) NAD index with the tropical Pacific SST anomalies a year later. (b) Partial correlations of the winter NAD index with the tropical Pacific SST anomalies a year later by removing the linear effect of the following AMJ PMM-wind index. (c) Scatterplot of the DJF NAD index versus the Niño4 index a year later, plotted only for those years in which the DJF NAD index has the same sign as the following AMJ PMM-wind index. (d) As for (c) but for only those years in which the DJF NAD index has the opposite sign as the AMJ PMM-wind index. In (a) and (b), areas with a correlation significant at or above the $95 \%$ confidence level are shaded. In (c) and (d), the correlation coefficient of the winter NAD and the Niño4 index a year later is given in the upper left corner.

Figure 11. Schematic representation of direct and indirect pathways through which the winter NAD affects the subsequent PMM. (a) The direct pathway: the winter NAD can directly affect the SST and surface winds over the NESP through concurrent anticyclonic flow associated with the NAD. (b) The indirect pathway: the winter NAD induces the SST cooling over the NTA region during spring, and the NTA SST cooling in turn produces a low-level anticyclonic flow anomaly over the NESP. A heat budget analysis reveals that the reduced latent heat flux (LHF) release from ocean to atmosphere due to the weakened trade winds on the west flank of the NAD-associated anticyclonic flow is very important for the development of positive SST anomalies over the subtropical pole of the PMM, while the anomalous upwelling due to anomalous easterlies on the south flank of 
the NAD-associated anticyclonic flow makes a major contribution to the development of negative SST anomalies over the equatorial pole of the PMM. 


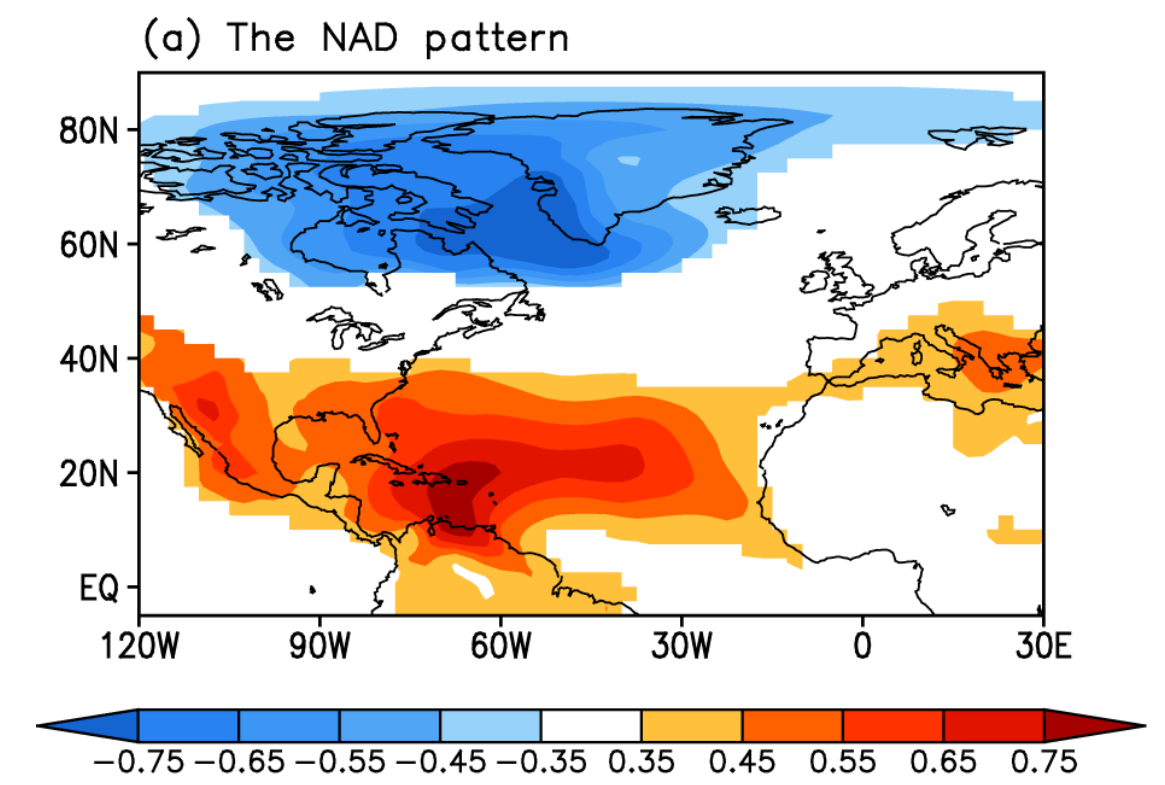

(b) The NAD index

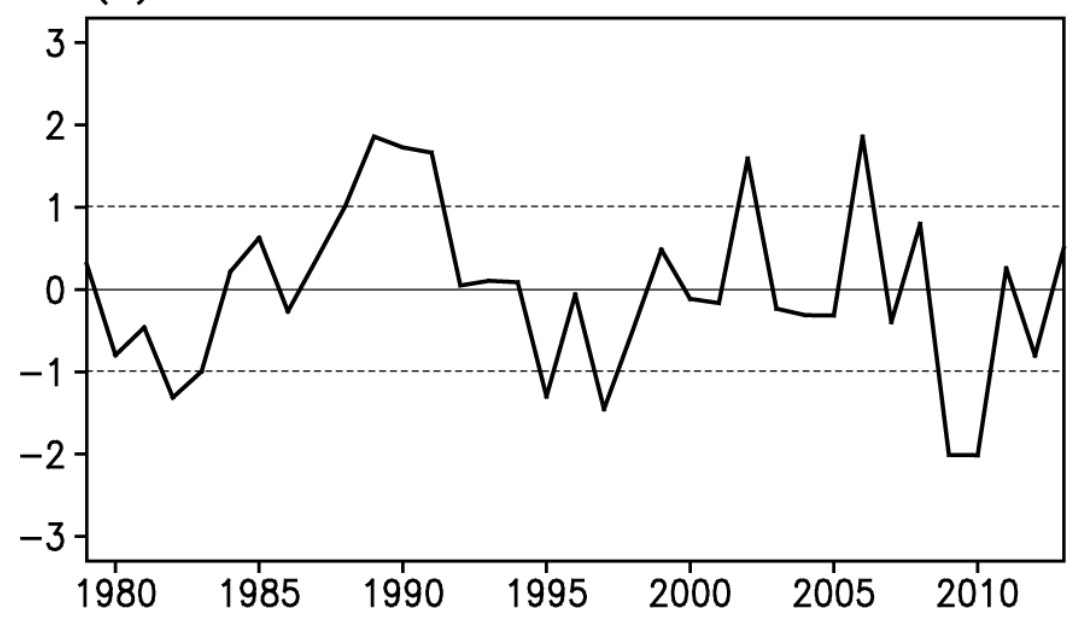

Figure 1. (a) Spatial pattern of winter [December-February (DJF)] averaged SLP anomalies correlated with the concurrent NAD index. Areas with a correlation significant at or above the $95 \%$ confidence level based on a two-tailed Student- $t$ test are shaded. (b) Time series of the winter (DJF) NAD index. To isolate the internal variability of the NAD independent of ENSO, the ENSO effect is removed from the NAD index using linear regression with respect to the Niño3.4 index (SST averaged over the region $\left.170-120^{\circ} \mathrm{W}, 5^{\circ} \mathrm{S}-5^{\circ} \mathrm{N}\right)$. 

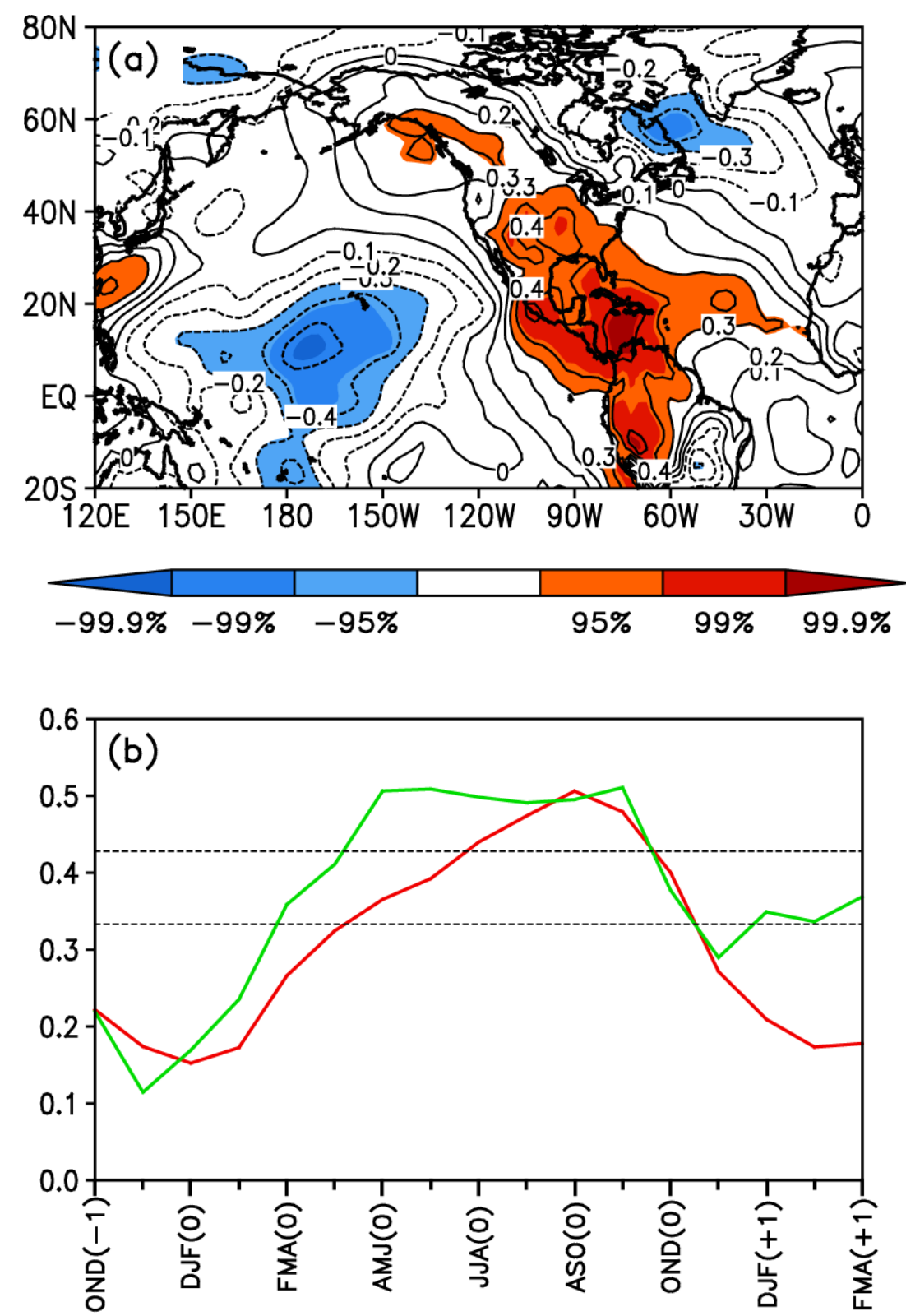

Figure 2. (a) Correlations of the AMJ-averaged PMM-wind index with the previous winter SLP anomalies. Areas with a correlation significant at or above the $95 \%$ confidence level are shaded. (b) Lead-lag correlations of the winter (DJF-averaged) NAD index with 3-month averaged PMM-wind (red line) and PMM-SST (green line) indices. The year in which the PMM develops is denoted as year(0), and the preceding and following years as year(-1) and year(+1), respectively. The horizontal dashed lines show the $95 \%$ and $99 \%$ confidence levels, respectively. 

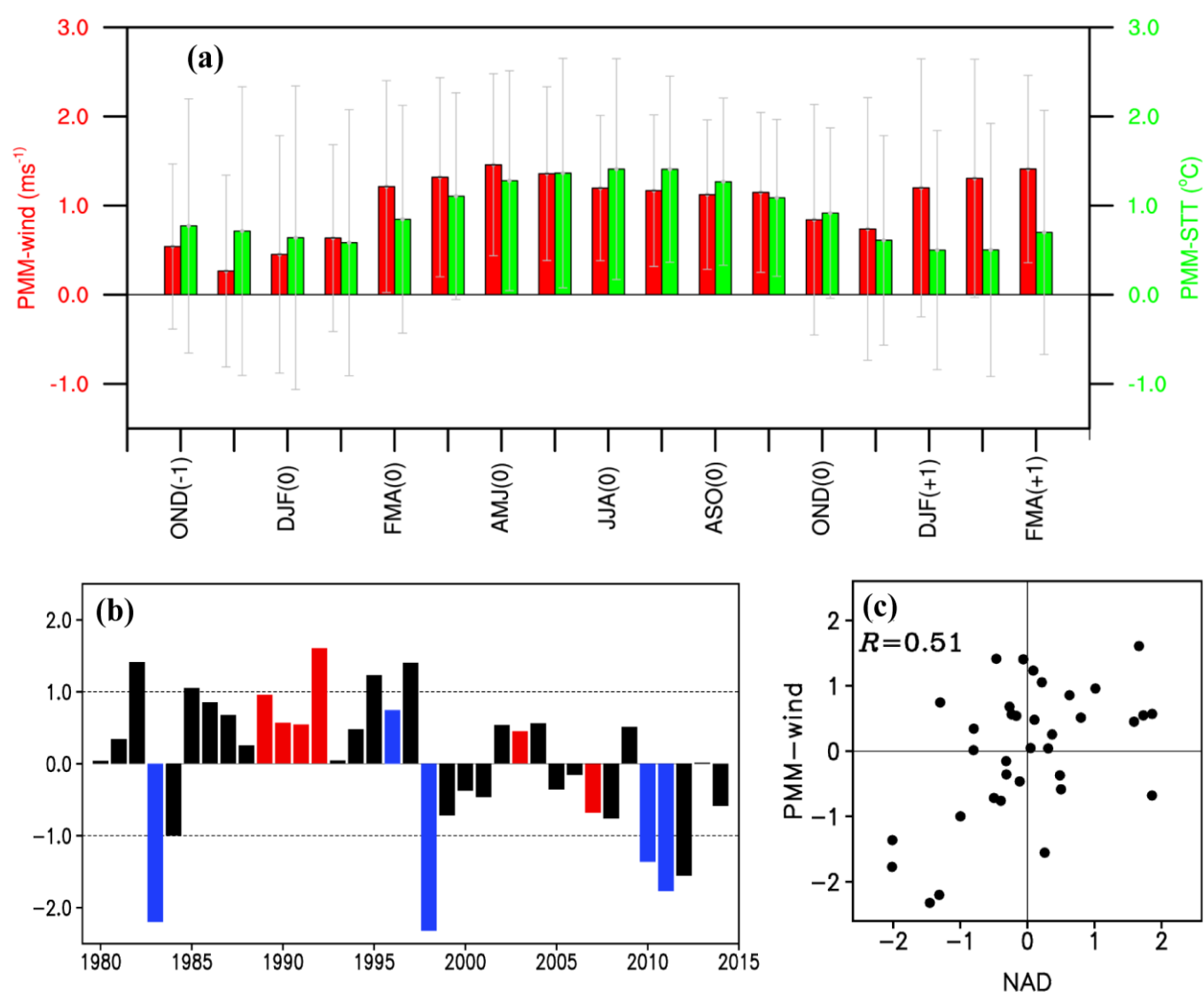

Figure 3. (a) Composite differences in the seasonal evolution of the PMM-wind (red bars; scale on the left y-axis) and PMM-SST (green bars; scale on the right y-axis) indices between strongly positive NAD cases (1988, 1989, 1990, 1991, 2002, and 2006) and strongly negative NAD cases (1982, 1995, 1997, 2009, and 2010). Error bars indicate the $95 \%$ confidence intervals based on a $t$-test. (b) Time series of the AMJ-averaged PMM-wind index from 1980 to 2014. Note that the years with strongly positive and negative NAD cases during the previous winter are denoted by red and blue bars, respectively. (c) Scatterplot of the DJF-averaged NAD index versus the following AMJ-averaged PMM-wind index. The correlation coefficient between the NAD and PMM-wind indices is given in the upper left corner. 


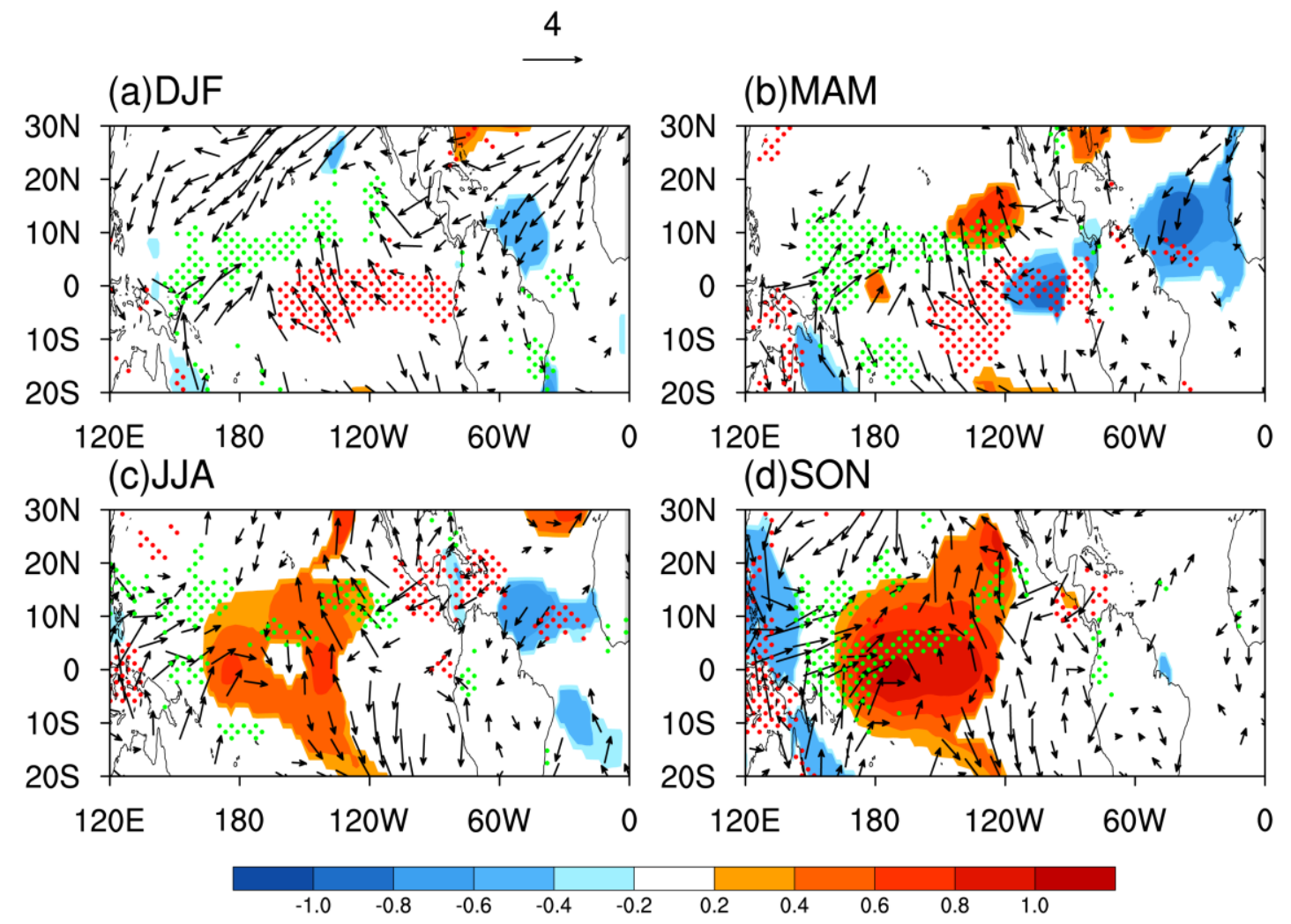

Figure 4. Composite differences of the 3-month averaged SST $\left({ }^{\circ} \mathrm{C}\right.$; shaded), surface wind ( $\mathrm{m} \mathrm{s}^{-1}$; vectors), and precipitation $\left(\mathrm{mm} \mathrm{day}{ }^{-1}\right.$; stippled) anomalies between strongly positive and negative NAD cases for (a) DJF concurrent with the NAD, and several lead times ((b) MAM, (c) JJA, and (d) SON). Only SST and surface wind anomalies significant at the $95 \%$ confidence level based on a $t$-test are shown. Positive (green) and negative (red) precipitation anomalies significant at the $95 \%$ confidence level are stippled. 

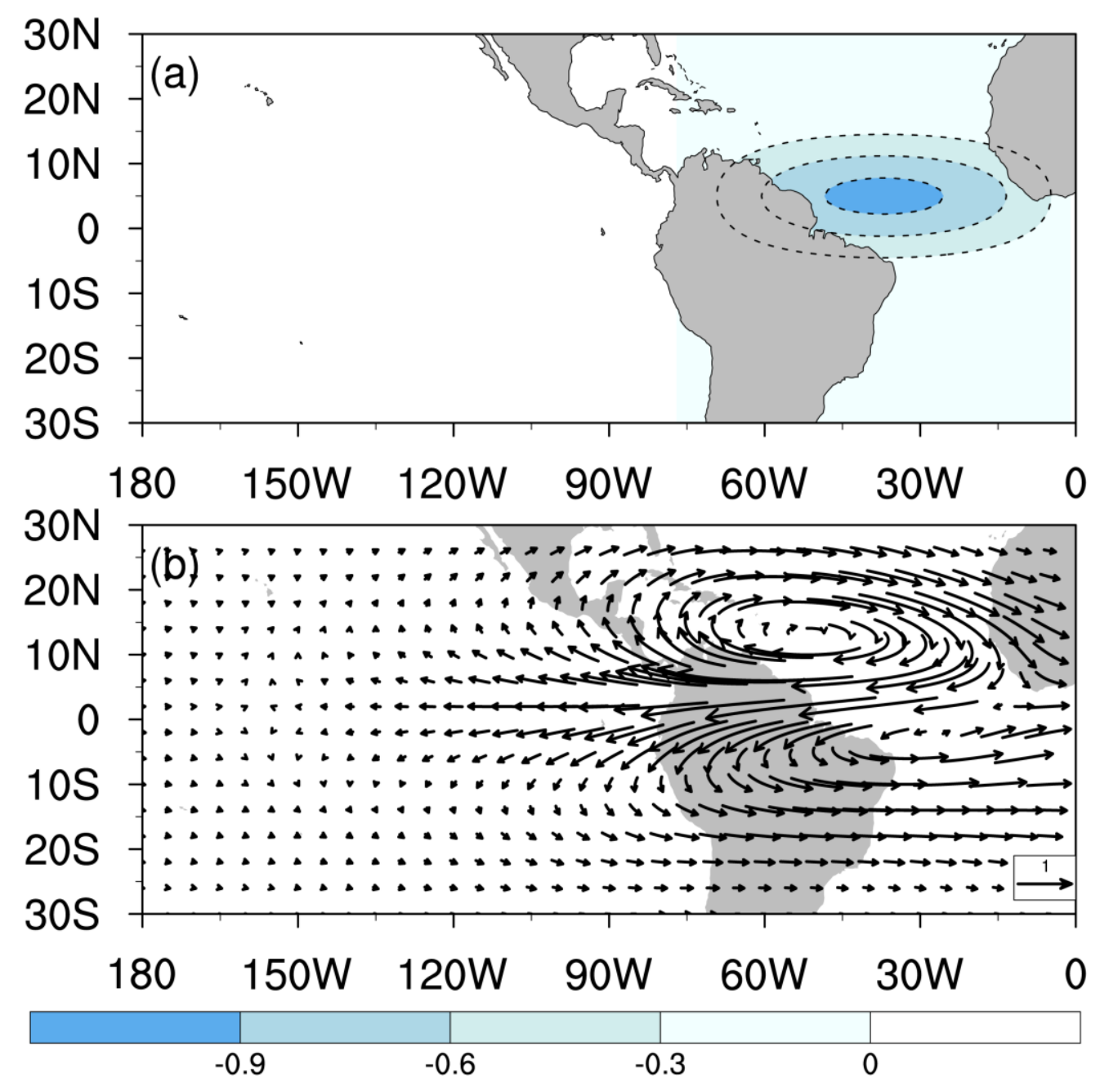

Figure 5. (a) Distribution of the prescribed ideal cooling over the NTA region for the Matsuno-Gill model. The location of the prescribed ideal cooling source is consistent with the distribution of maximum negative precipitation anomalies during MAM in Figure 4b, with strength decreasing from the center to the surroundings. (b) Analytical solutions for horizontal winds forced by the cooling in (a). 
(a) Subtropical pole

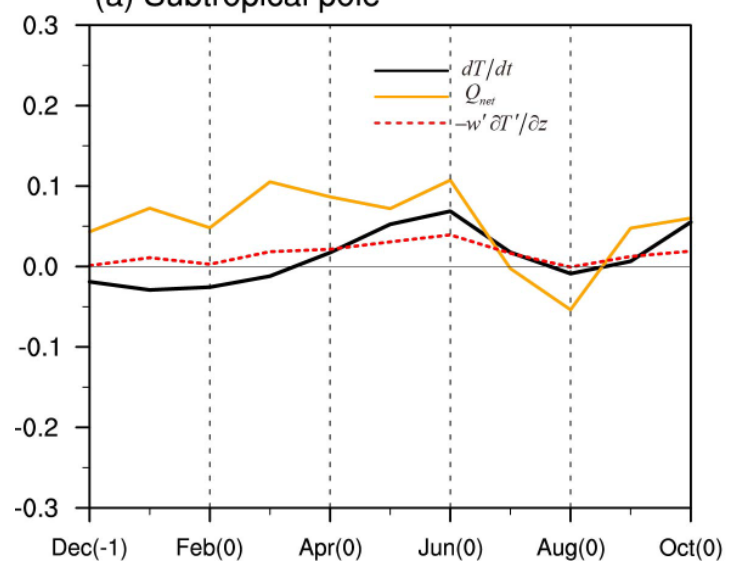

(b) Equatorial pole

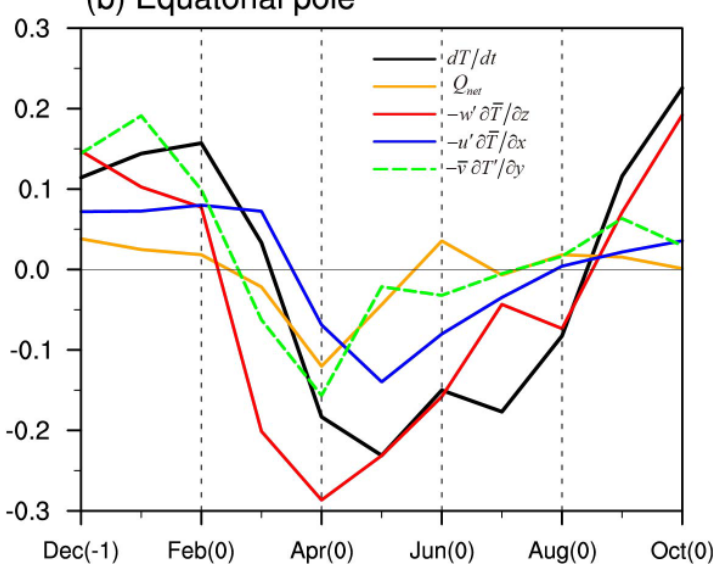

Figure 6. (a) Composites differences of dominant terms (Unit: ${ }^{\circ} \mathrm{C}$ month ${ }^{-1}$ ) in the SST equation for the subtropical $\left(140-110^{\circ} \mathrm{W}, 8-20^{\circ} \mathrm{N}\right)$ pole of the PMM between strongly positive and negative NAD cases. (b) As in (a) but for composites differences of dominant terms in the SST equation for the equatorial $\left(120-70^{\circ} \mathrm{W}\right.$, $5^{\circ} \mathrm{S}-5^{\circ} \mathrm{N}$ ) pole of the PMM. 

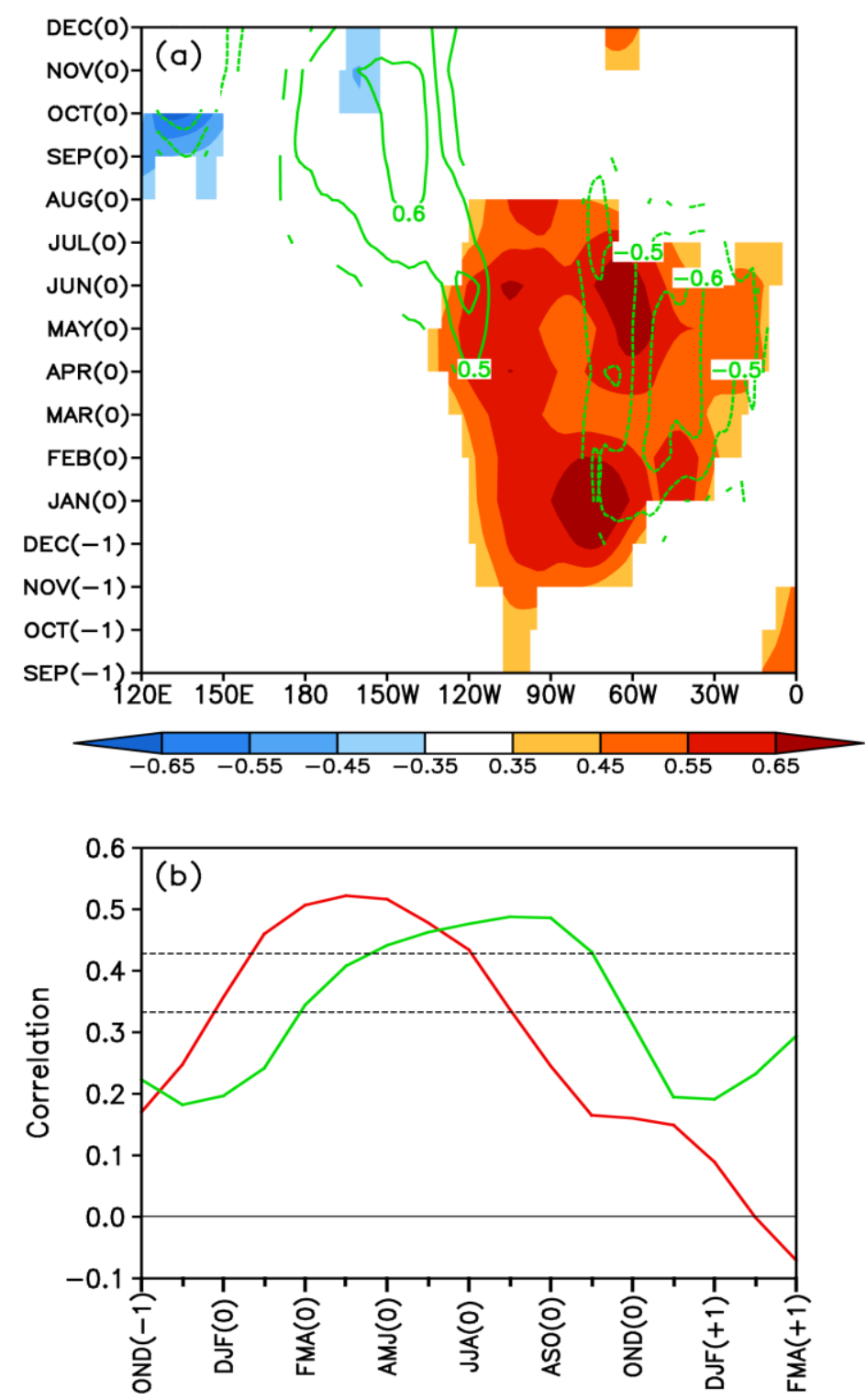

Figure 7. (a) Lead-lag regressions of the 3-month running mean subtropical stream function at $850 \mathrm{hPa}$ (meridionally averaged over $9^{\circ}-29^{\circ} \mathrm{N} ; 10^{7} \mathrm{~m}^{2} \mathrm{~s}^{-1}$; shaded) and SST (meridionally averaged over $5^{\circ}-20^{\circ} \mathrm{N}$; ${ }^{\circ} \mathrm{C}$; contours) onto the winter [December(-1)-February(0)] NAD index from September(-1) to December(0). Only stream function and SST anomalies significant at the 95\% confidence level are shown. (b) Lead-lag correlations of the DJF NAD index with 3-month averaged NTA SST area-averaged over $\left(85^{\circ} \mathrm{W}-20^{\circ} \mathrm{E}, 0-15^{\circ} \mathrm{N}\right)$ (red line), and lead-lag correlations of the MAM NTA SST with 3-month averaged PMM-SST index (green line). The horizontal dashed lines show the $95 \%$ and $99 \%$ confidence levels, respectively. 
(a) PMM-wind

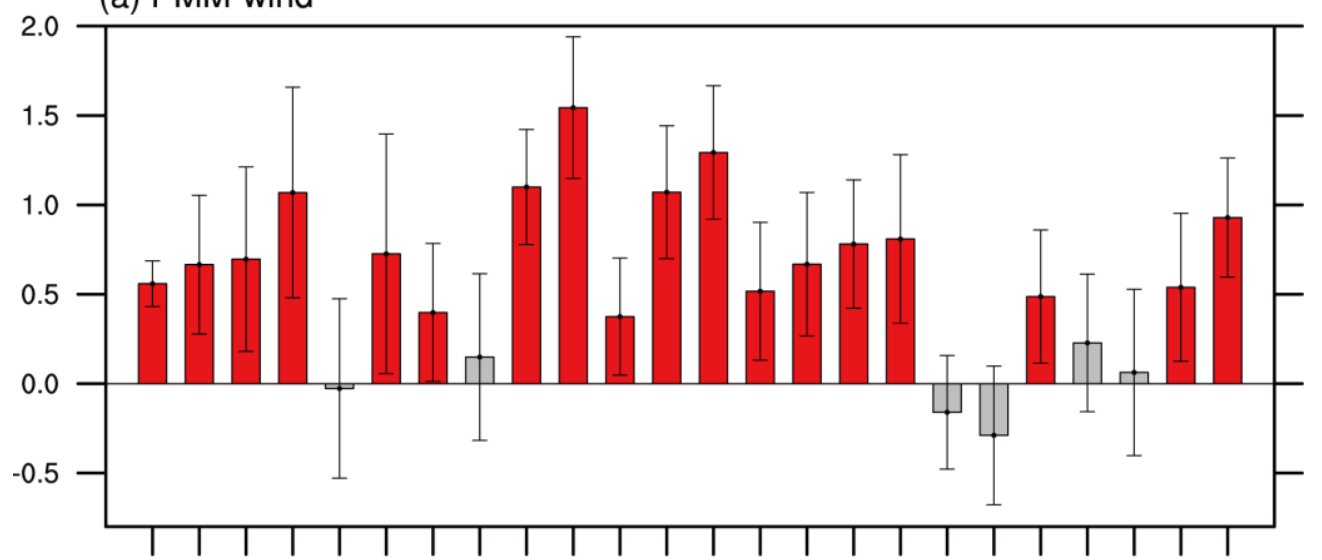

(b) PMM-SST

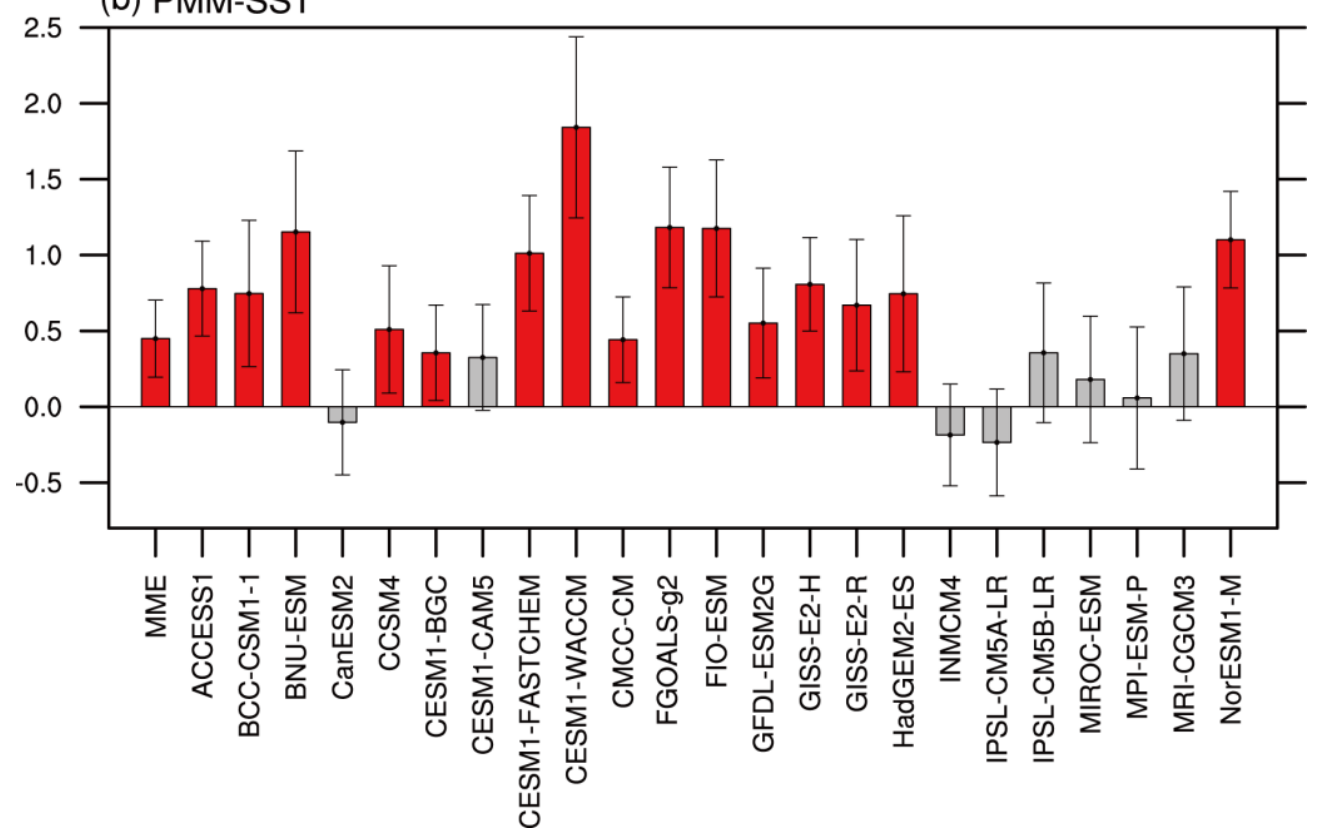

Figure 8. Composite differences of the AMJ-averaged (a) PMM-wind and (b) PMM-SST indices between strongly positive and negative NAD cases in 23 CMIP5 models. Also shown the multi-model ensemble (MME) of 23 CMIP5 models. Error bars indicate the $95 \%$ confidence intervals based on a $t$-test. 

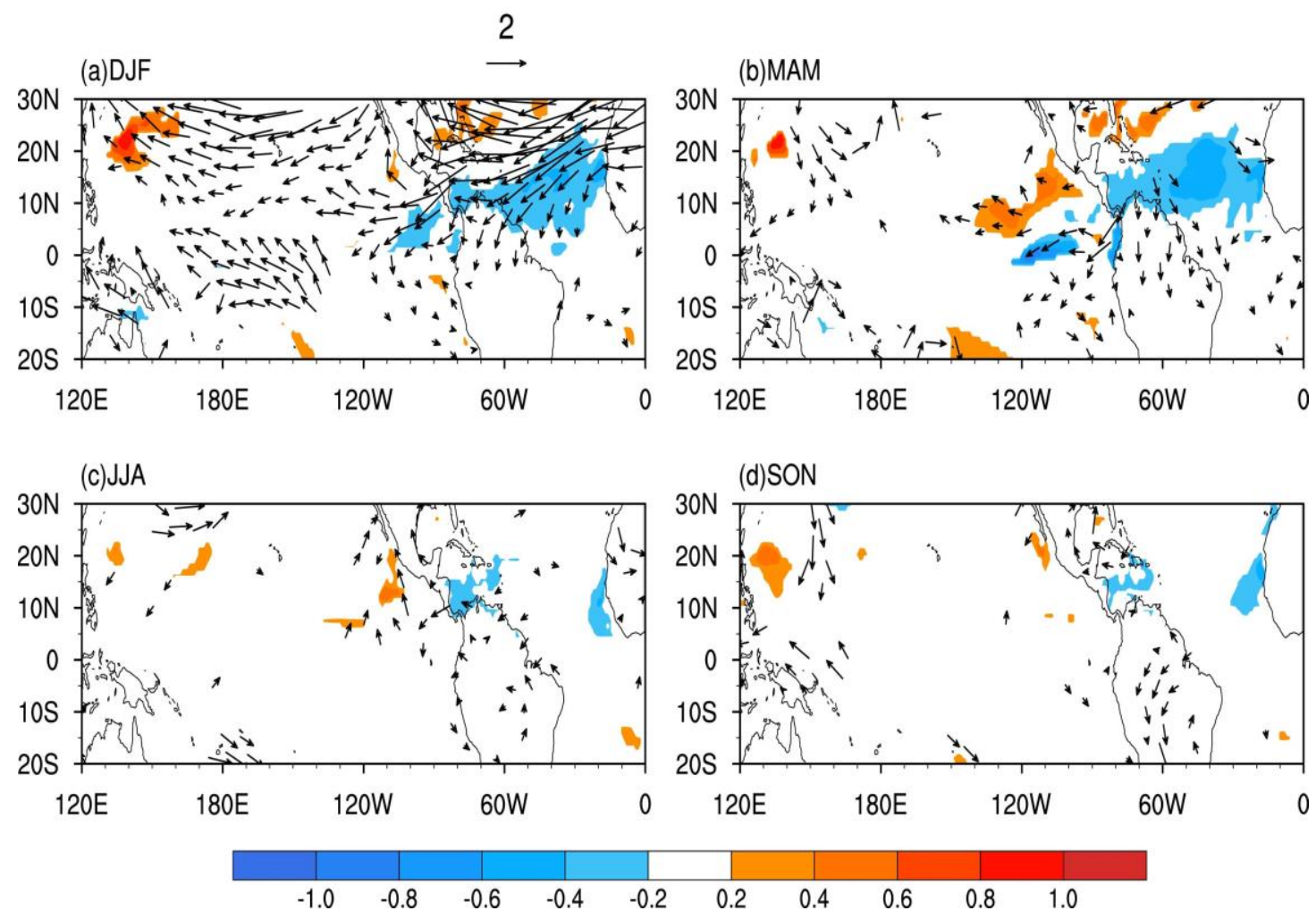

Figure 9. Ensemble-mean composite differences of the 3-month averaged SST $\left({ }^{\circ} \mathrm{C}\right.$;

shaded) and surface wind ( $\mathrm{m} \mathrm{s}^{-1}$; vectors) anomalies between strongly positive and negative NAD cases from 23 CMIP5 models for (a) DJF concurrent with the NAD, and several lead times ((b) MAM, (c) JJA, and (d) SON). Only SST and surface wind anomalies significant at the $95 \%$ confidence level based on a $t$-test are shown. 

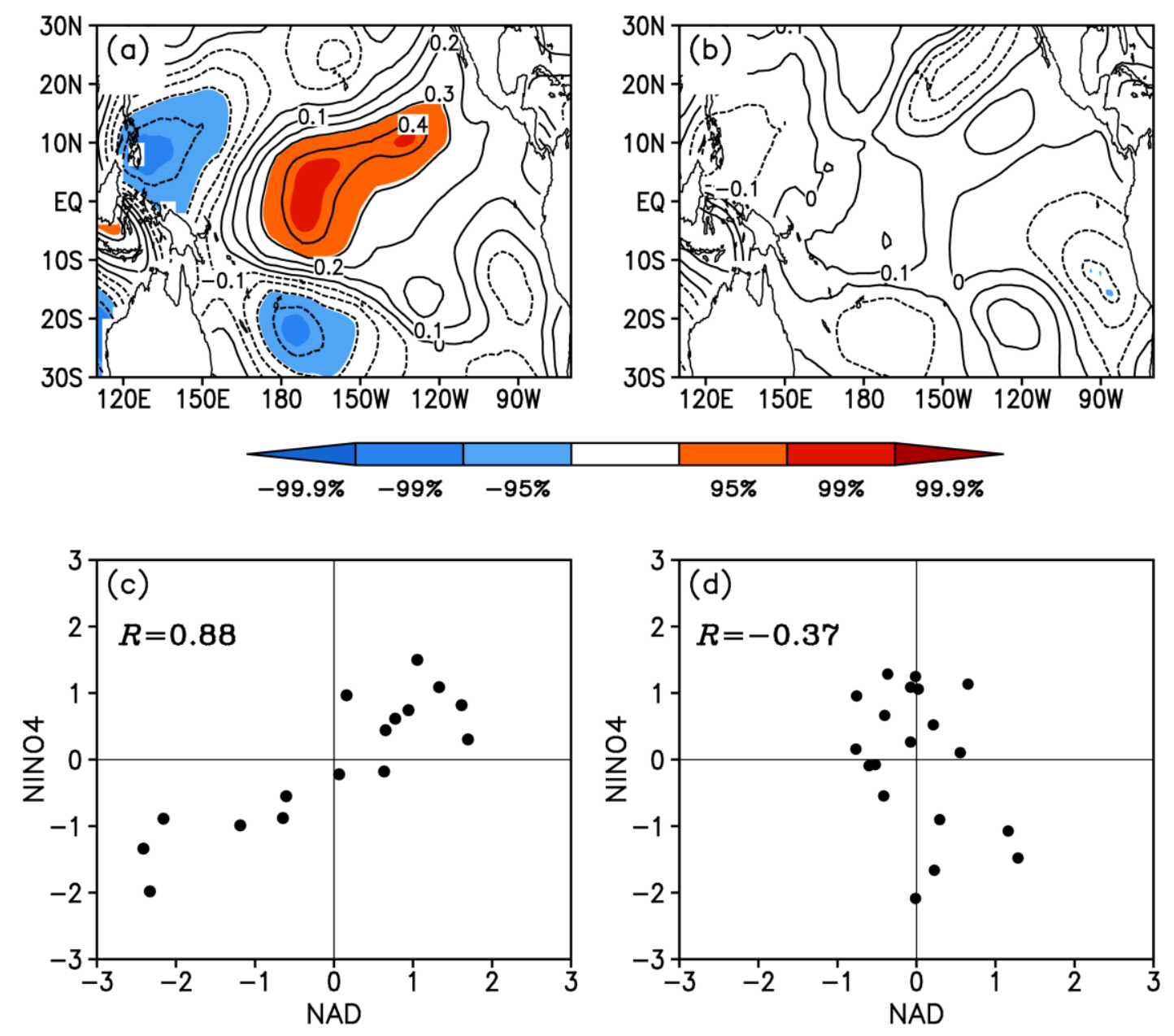

Figure 10. (a) Correlation map of the winter (DJF) NAD index with the tropical Pacific SST anomalies a year later. (b) Partial correlations of the winter NAD index with the tropical Pacific SST anomalies a year later by removing the linear effect of the following AMJ PMM-wind index. (c) Scatterplot of the DJF NAD index versus the Niño4 index a year later, plotted only for those years in which the DJF NAD index has the same sign as the following AMJ PMM-wind index. (d) As for (c) but for only those years in which the DJF NAD index has the opposite sign as the AMJ PMM-wind index. In (a) and (b), areas with a correlation significant at or above the 95\% confidence level are shaded. In (c) and (d), the correlation coefficient of the winter NAD and the Niño4 index a year later is given in the upper left corner. 
(a)

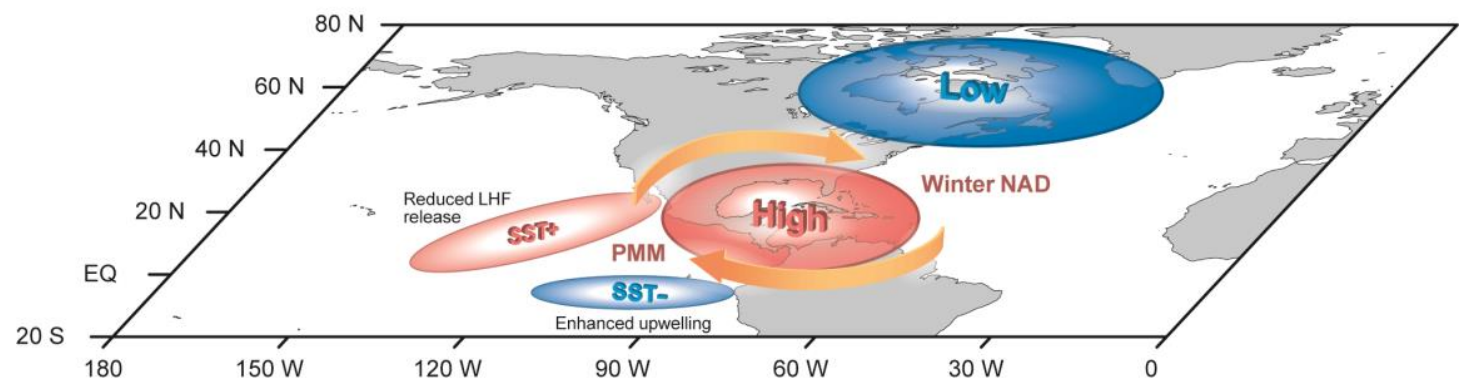

(b)

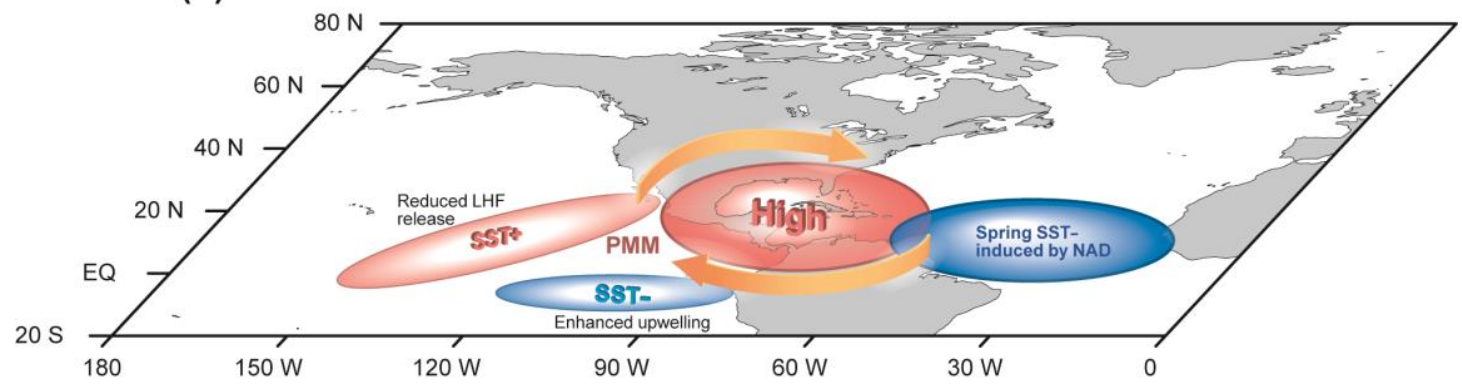

Figure 11. Schematic representation of direct and indirect pathways through which the winter NAD affects the subsequent PMM. (a) The direct pathway: the winter NAD can directly affect the SST and surface winds over the NESP through concurrent anticyclonic flow associated with the NAD. (b) The indirect pathway: the winter NAD induces the SST cooling over the NTA region during spring, and the NTA SST cooling in turn produces a low-level anticyclonic flow anomaly over the NESP. A heat budget analysis reveals that the reduced latent heat flux (LHF) release from ocean to atmosphere due to the weakened trade winds on the west flank of the NAD-associated anticyclonic flow is very important for the development of positive SST anomalies over the subtropical pole of the PMM, while the anomalous upwelling due to anomalous easterlies on the south flank of the NAD-associated anticyclonic flow makes a major contribution to the development of negative SST anomalies over the equatorial pole of the PMM. 